\title{
Behavioral Capitalism - A New Variety of Capitalism Gains Power and Influence
}

\author{
Andreas Herteux \\ Erich von Werner Society
}

In the upcoming Age of Collective Individualism, a new variety of capitalism has established itself, which uses human behavior, which used to serve primarily as a complementary raw material, as a production factor and has thus established completely new business models and markets: Behavioral Capitalism.

This new form of capitalism, which has benefited from the changing times, the Stimulus Society and the development of the Homo stimulus, is so dominant and influential that it is already exerting a considerable influence on economic, social and political life. Nevertheless, behavioral capitalism has so far been hardly noticed, which is why it is time to give it a scientific basis and thus initiate a discussion about it.

Keywords: Society, Economy, Politics, Behavioral Capitalism, Surveillance Capitalism, Homo Stimulus, Stimulus Society, Erich von Werner Society, Variety of Capitalism

\section{INTRODUCTION}

- Human behavior is a usable raw material

- This raw material has developed into a production factor due to technological progress.

- This production factor has led to new business models that now have a massive impact on economic, political and social life.

- It is therefore necessary to speak of a new variation of capitalism: Behavioral Capitalism.

- This new form of capitalism is not yet understood as such, which entails the danger that it creates power and market relations that can hardly or only with great difficulty be corrected later.

The world is experiencing a change of times and an era of change. Dynamic, fast and at which point can this be recognized more clearly than by technological progress, which powerfully and at an incredible speed changes personal and community life and leaves almost no field untouched, be it politics, society or economy. Within the framework of this process, influence has shifted and new ones have been established. But all that almost imperceptibly, almost creepingly in the shadows and yet at the end almost all of it tangent. Technology more than ever means power and this special influence through the smart world, can be found today in the western world astonishingly bundled with a few companies, which naturally have little interest in explaining the risks of their activity too publicly, because they primarily see the opportunities of their actions and not the dangers. Who will blame them? How many 
people really understand their business models? Didn't they seem to come out of nowhere, these billiondollar companies that are now indispensable?

This new influence of the large technology groups, which often exist only for a few years, is astonishing and astonishing, as is the development that their products have become an indispensable part of everyday life for many people and society at breakneck speed. A silent conquest and yet they are much more than just clever business models that can be easily integrated into the existing. These companies are only players on a playing field that has made their existence and growth possible in the first place. One thing that has too often been underestimated and overlooked so far is Behavioral Capitalism.

With this term, the child itself was derived and baptized by the author of these lines, the feeling for the shift of power relations gets an ordering, well-founded framework and becomes comprehensible. The accumulation of power can no longer hide behind the mechanisms of the new, but is clearly visible in the light. A necessity, because an unbridled and unbridled behavioral capitalism is even more dangerous than an angry financial capitalism, because it needs not only capital, but man as a whole to harvest. Anytime, any day. Yes, the phenomenon was palpable. Now it finds its analysis and order. Behavioral Capitalism must therefore be identified and interpreted in order to be able to deal with it self-confidently and positively. The wild horse needs dressage, otherwise it will go through at the end.

In isolated cases, and this should be noted, there are already further attempts to give the new era a verbalized form, of which in particular Shoshana Zuboff's concept of Surveillance Capitalism is to be mentioned, but this, and forgive me this word, does not go far enough to sufficiently explain the corresponding global changes and also concentrates strongly on possible negative aspects of a raging development, which can be both a blessing and a curse, the truth usually lies in the middle.

The model of behavioral capitalism therefore follows a different, neutral approach and has little in common with surveillance capitalism other than that both want to approach the same phenomenon. Nevertheless, it is recommended to work with this preparation. However, since these pages are only intended to briefly describe Behavioral Capitalism, a deeper examination of other concepts can only take place separately.

Let us therefore begin with the actual topic and immediately with a definition:

\section{Behavioral Capitalism is a variant of capitalism in which human behavior becomes the central factor for the production and provision of goods and services.}

The key to understanding this new form of capitalism is to look at human behavior as a usable resource. From this, as far as it can be sufficiently won, on the one hand the needs of the people can be derived, but on the other hand also prognoses for future action. On the basis of this raw material, products and services can therefore be produced that correspond to the needs or future behavior. It is also possible to trade the data itself on the market. How behavior is defined?

\section{Behavior means acting, tolerating as well as not acting. The processes can be conscious or unconscious. It is influenced and produced by stimuli.}

All of this may sound terribly abstract, but on closer inspection, behavior has always been used as a raw material, though not always so. We do not want to refer to the sale of indulgences in the Middle Ages, but to the insurance industry. It is a prime example of how the behavior of the customer, often in the person of the representative, is researched, then evaluated by the company, and finally used to improve existing products, i.e. insurance, and to create new services. Only in this way were creative developments such as safeguarding one's own death conceivable. Since these are immaterial, i.e. intangible goods, the behavior of interested parties and customers is of outstanding importance.

Basically, it has always been a production factor, at least in these areas, and it is with this very idea that we can approach this new form of capitalism, because the recognition that the needs and behavior of potential customers are an important component of being able to offer and sell products and services effectively is neither original, nor does it require more in-depth study. 
But now the conditions have changed, because technological development has led to new business models that have gained such an influence that they raise the question of whether they have long since developed into an independent form of capitalism, behavioral capitalism. This brings us to the central thesis of this paper, which is that new possibilities of behavioral skimming have turned the raw material into a factor of production and thus into a variant of capitalism in its own right.

\section{The central production factor of behavioral capitalism is human behavior.}

Not that one did not always want to know as much as possible, but only with the aforementioned technological development did the problem of the difficult acquisition of behavioral data disappear into thin air within a very short time. It is therefore hardly surprising at what speed large technology companies such as Amazon, Facebook or Google emerged and began to collect data, use behavior according to capitalist methods and embed people bit by bit. Algorithms and automation made possible what humans would not have been able to do.

They were the great behavioral capitalists. Now they analyse the homo stimulus and try to generate information or data on the basis of its behavior or to offer or mediate products and services. Tailored to the individual. The raw material "behavior" became a production factor.

This new factor of production is now so important that it has also become indispensable for classical and financial capitalism, since knowledge of current behavior, composed of vast amounts of data obtained, makes it possible in many cases to assess or influence future behavior.

Today, behavior is also a central production factor for classical and Financial Capitalism and complements labor, land and capital.

This behavior is then used directly as merchandise or processed into satisfaction and/or forecast products in a production process.

A satisfaction product aims to satisfy human needs. A prognosis product predicts future human behavior. Behavioral data can also be traded without further processing.

Algorithms and more and more artificial intelligence take over this task. To simplify, we summarize this decentralized process in the descriptive metaphor of the behavioral factory.

The storage of behavior as well as the processing to satisfaction and prognosis products take place in the behavior factory.

So much for the basic definitions and the history of development. In the following, the functionality and the value creation process of behavioral capitalism will be examined in more detail. 


\section{FIGURE 1}

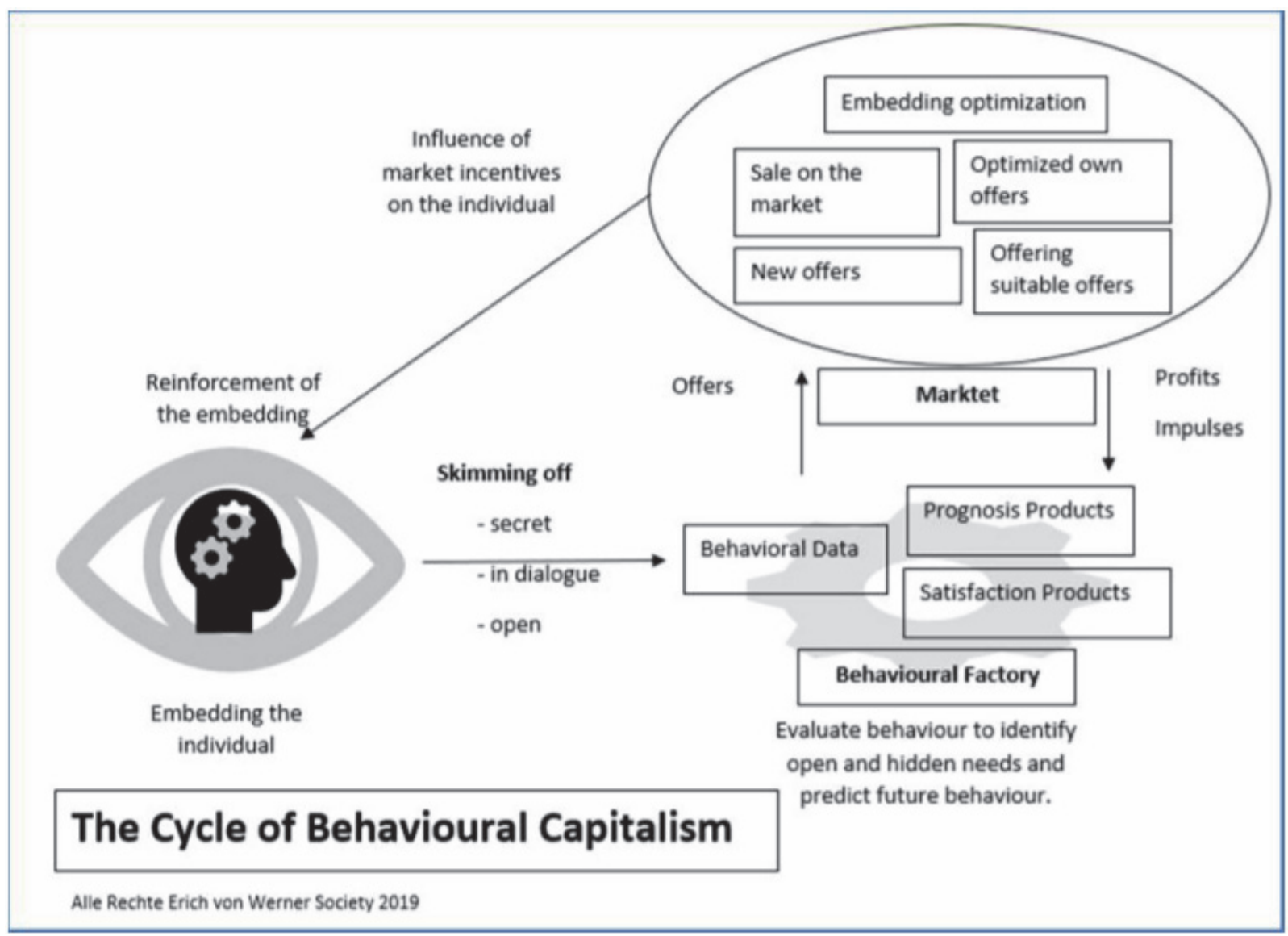

\section{Absorption of Behavioral Data}

Behavioral Capitalism is based on the raw material and production factor behavior, which is created by the reaction of the individual to stimuli. He must first win this by skimming. There have always been such attempts, but it was the technological progress driven by the change of times that made automated harvesting in large quantities possible. The skimming process has three variants:

\section{Open Skimming}

In this case, the individual is aware that his or her data will be used to produce certain corresponding forecast and satisfaction products.

A typical example would be the input in a search engine. His personal behavior or interest is used openly to present him with the desired result. In just one minute, for example, 2017 will be a worldwide event:

- $\quad 3.8$ million Google searches

- 47,000 Instagram Photo Uploads

- 4.1 million Youtube video clicks

- 530,000 snap chat photo shares

- 456,000 Twitter message transmissions

These figures impressively prove that many behavioral data are transmitted voluntarily in many cases, because this creates added value for the user. 


\section{Dialogic Skimming}

In the dialogical skimming off, the individual and a machine (algorithm, AI) enter into a dialogue process that serves not only to identify needs, but also to estimate future behavior. In doing so, both sides react to stimuli and it is now possible to disclose needs that the user may not have been aware of. The interaction can be open or hidden. What is important is that the process goes beyond an action.

\section{Hidden Skimming}

With concealed skimming, the behavior is harvested and further processed or resold without the knowledge of the user. An example would be when profile data of an individual is used in a social network to develop commercial products and services to use for behavior manipulation or control. The model case here would be the use of 87 million Facebook user data from Cambridge Analytica for the election campaign of Donald Trump in 2017.

The boundaries between the individual variants are of course fluid. For example, the majority of search engine users are now well aware that the results are accompanied by product ads from the same range of topics. Similarly, social media users should be aware that their data is being used for embedding. A rigid separation of the types of levy therefore makes little sense.

\section{Transformation in the Behavioral Dactory}

The data volumes obtained are now stored in the behavioral factory, a metaphor to represent a complicated and decentralised processing process more plastically, and processed in parts into products. Forecast products as well as satisfaction products are produced.

Forecast products are used to estimate the future behavior of an individual. A typical example would be a user of a social network who is interested in hiking, presents photos and documents participation in events. The algorithm can now read this data and supplement it with other information such as age, place of residence, brand inclinations, style, etc. The algorithm can also read the data from the data. Paired with the reading of the browser history, which can happen even if you are no longer logged in to the corresponding network, a forecast product is created, the result of which could be, for example, that exactly this user is highly likely to set off on the corresponding tours again in summer. It would therefore make sense to virtually confront him with suitable services (e.g. travel offers) or products (e.g. hiking boots) shortly beforehand. The forecast product opens the door for a targeted approach.

Satisfaction products, on the other hand, are specifically aimed at satisfying identified needs. Not in the future, but in the present. It is interesting to note that a satisfaction product can refer both to a need that the user is aware of and to a need that he has not yet reflected on, but which results from the analysis of behavior. Thus, it is precisely satisfaction products, but also prognosis products, that have the function of revealing the inner needs of the individual and can thus be an important element of self-realization.

\section{Trading on the Market}

Both prognosis and satisfaction products as well as the behavior itself can be used or sold by the data collector himself. This generates massive profits, which are usually reinvested. Not necessarily only in the previous business model, but also in other fields that invite networking. The following opportunities therefore arise for the market:

\section{Offering Suitable Offers}

The data is used to offer suitable offers to the individual. This can consist of own services and products, combined, however, these are usually with the advertisement for third parties. The core of the business model can still be seen here today.

Overall, it is estimated that $25 \%$ of global advertising revenues are now generated by Facebook and Google, two of the best examples of applied Behavioral Capitalism. By 2016, it was still 20\%. Tendency rising. 


\section{New Offers}

Behavior makes it necessary to design entirely new products in order to satisfy the needs identified from them. The idea of deriving the necessary innovations and further developments from market observation is as old as economic activity itself, but thanks to the new possibilities of siphoning off a raw material that was previously difficult to extract, it has reached a completely new dimension.

\section{Optimization of Own Offers}

The own offers are improved and adapted by behavior products and appropriate feedback. This applies both to the collectors of the data and to their customers. In particular, the learning machine relies on these reactions to constantly improve its functions.

\section{Sale on the Market}

The data volumes are made available to third parties raw or already as processing products for their own business activities.

\section{Embedding Optimization}

The collective individualism knows the embedding of man the creation of an individual reality. Behavioral Capitalism contributes to this through a continuous cycle of behavioral skimming.

FIGURE 2

\section{Embedding process}

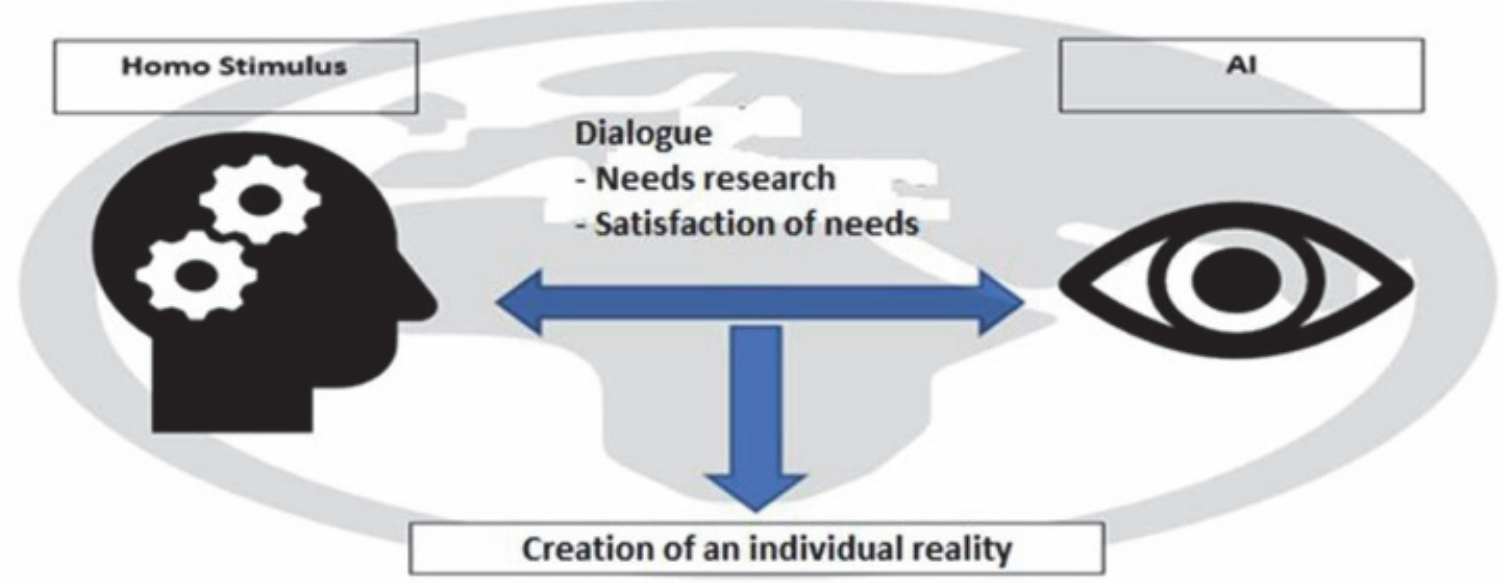

Alle Rechte Erich von Werner Gesellschaft 2019

\section{Stimulation of the Individual to React}

In the ideal case, the individual reacts to the stimuli offered and thus creates new behavior, which in turn can be skimmed off. The result is a cycle of embedding, which in the end can lead to the creation of an individual reality.

In a complete collective individualism, which of course presupposes a constant technical development, the skimmed-off would now sink bit by bit into an individualized reality. However, this is still incomplete due to the presence of milieu fights. At the same time, the raw material behavior and the investment capital accumulate, which further improves the possibilities of the behavior factory and 
skimming. A cycle develops. The game, driven by the machine, starts from the beginning. Thus, on the one hand, it causes the embedding of man, but at the same time it also causes the further drifting apart of the social milieus.

\section{Inventory and Outlook}

Behavioral Capitalism is a variant of capitalism that, like financial capitalism, is difficult to identify in its effects and therefore plays only a subordinate role in public perception and on the political agenda. He cleverly uses this to spread and consolidate himself, which in capitalism is often characterized by the emergence of monopolies or oligopolies. This is impressively demonstrated by the real situation of the technology groups and their market power.

Behavioral Capitalism has therefore become firmly established, but without being perceived as such. State-of-the-art technology enables a never-before-seen embedding that can penetrate into the most intimate areas of the individual. A development that requires closer scrutiny and must not continue to take place in the shadows, for an unleashed Behavioral Capitalism would be an even stronger force than Financial Capitalism ever was. He would be a means of domination.

The presentation of this development was deliberately neutral, as it entails both opportunities and risks. The embedding of the individual in his own world, which serves his own fulfilment of needs and self- realisation, is at first not negative, especially since this does not have to be designed in a closed way. On the other hand, of course, there is a central world of who ultimately controls the stimuli and the data and whether the behavior or even one's own reality is manipulated. This, like the model of behavioral capitalism, is now to be released for discussion.

\section{ACKNOWLEDGEMENT}

This contribution by Andreas Herteux was first published on the official presence of the Erich von Werner Society. It can also be found in these books:

- "First Foundations of Behavioral Capitalism: A New Variety of Capitalism Gains Power and Influence", Andreas Herteux, Erich von Werner Verlag, 2019, ISBN 978-3981900675, DOI 10.5281/zenodo.3469568

- Erste Grundlagen des Verhaltenskapitalismus: Bestandsaufnahme einer neuen Spielart des Kapitalismus", by Andreas Herteux, published by Erich von Werner Verlag, 2019, ISBN 978-3981900651, DOI 10.5281/zenodo.3469587.

- "Premiers fondements du capitalisme comportemental: Un inventaire d'une nouvelle variétéde capitalism", Andreas Herteux, Erich von Werner Verlag, 2019, ISBN 9783981900682, DOI 10.5281/zenodo.3517802

- Le prime basi del capitalismo comportamentale: Inventario di una nuova varietà di capitalismo, Andreas Herteux, Erich von Werner Verlag, 2019, ISBN 9783948621025, DOI 10.5281/zenodo.3517835

- Primeiras Fundações do Capitalismo Comportamental: Um inventário de uma nova varied-ade de capitalismo" Andreas Herteux, Erich von Werner Verlag, 2019, ISBN 9783948621018, DOI 10.5281/zenodo.3517837

- "Primeros fundamentos del capitalismo conductual - Un inventario de una nueva variedad de capitalismo," Andreas Herteux, Erich von Werner Verlag, 2019, ISBN 9783948621001, DOI 10.5281/zenodo.3517839

- "Первые основы поведенческого капитализма: Инвентаризация нового разнообразия капитализма, Andreas Herteux, DOI 10.5281/zenodo.3517841

- De eerste stichtingen van het gedragskapitalisme - Een inventaris van een nieuwe variëteit van het kapitalisme, Andreas Herteux, Erich von Werner Verlag, 2019, ISBN 978-3-948621-03-2, DOI 10.5281/zenodo.3521230 
- Pierwsze fundamenty kapitalizmu behawioralnego - Inwentaryzacja nowej odmiany kapitalizmu, Andreas Herteux, Erich von Werner Verlag, 2019, ISBN “978-3-948621-05-6 DOI $10.5281 /$ zenodo.3521294

\section{REFERENCES}

Herteux, A. (2019). Der Homo stimulus - Die Schaffung eines neuen Menschen, geprägt von Reizgesellschaft und Verhaltenskapitalismus, im Zeitalter des kollektiven Individualismus. http://doi.org/10.5281/zenodo.3556808

Herteux, A. (2019). First Foundations of Behavioral Capitalism: A New Variety of Capitalism Gains Power and Influence. Erich von Werner Verlag. ISBN: 978-3981900675, DOI: $10.5281 /$ zenodo. 3469568

Herteux, A. (2019). The Homo Stimulus: The creation of a new human being - shaped by the stimulus society and behavioral capitalism - in the age of collective individualism. http://doi.org/10.5281/zenodo.3556810

Zuboff, S. (2019, January 31). The Age of Surveillance Capitalism: The Fight for the Future at the New Frontier of Power Profile Books. 